University of Texas Rio Grande Valley

ScholarWorks @ UTRGV

$10-2015$

\title{
Understanding health information technology adoption: A synthesis of literature from an activity perspective
}

Jun Sun

The University of Texas Rio Grande Valley, jun.sun@utrgv.edu

Zhe Qu

Fudan University

Follow this and additional works at: https://scholarworks.utrgv.edu/is_fac

Part of the Business Commons, and the Health Information Technology Commons

\section{Recommended Citation}

Sun, J., \& Qu, Z. (2015). Understanding health information technology adoption: A synthesis of literature from an activity perspective. Information Systems Frontiers, 17(5), 1177-1190. https://doi.org/10.1007/ s10796-014-9497-2

This Article is brought to you for free and open access by the Robert C. Vackar College of Business \& Entrepreneurship at ScholarWorks @ UTRGV. It has been accepted for inclusion in Information Systems Faculty Publications and Presentations by an authorized administrator of ScholarWorks @ UTRGV. For more information, please contact justin.white@utrgv.edu,william.flores01@utrgv.edu. 


\title{
Understanding Health Information Technology Adoption:
}

\section{A Synthesis of Literature from an Activity Perspective}

\author{
Dr. Jun Sun \\ 1201 W University Drive, College of Business and Entrepreneurship, University of Texas Rio \\ Grande Valley, Edinburg, TX 78539, USA \\ Dr. Zhe Qu* \\ 670 Guoshun Road, School of Management, Fudan University, Shanghai, 200433, China
}

* Corresponding Author. This research was partially supported by the NIH grant \#5G11HD038438-08 (first author), and National Natural Science Foundation of China grant \#71002012 (second author). 


\begin{abstract}
The vast body of literature on health information technology (HIT) adoption features considerably heterogeneous factors and demands for a synthesis of the knowledge in the field. This study employs text mining and network analysis techniques to identify the important concepts and their relationships in the abstracts of 979 articles of HIT adoption. Through the lens of Activity Theory, the revealed concept map of HIT adoption can be viewed as a complex activity system involving different users, technologies and tasks at both the individual level and the social level. Such a synthesis not only discloses the current knowledge domain of HIT adoption, but also provides guidance for future research on HIT adoption.
\end{abstract}

Key words: Activity Theory, health information technology, system adoption, text mining, network analysis, literature synthesis. 


\section{Introduction}

Health information technology (HIT) has been recognized as one of the most important means to improve the quality, efficiency and effectiveness of healthcare services (Agarwal et al. 2010; Bhattacherjee et al. 2006; Carstens et al. 2009; Goldschmidt 2005; Menon et al. 2000; Menon and Lee 2000; Teoh et al. 2012). However, a number of studies have indicated that the adoption of HIT remains limited (Anderson 2007; Bhattacherjee et al. 2006; Ford et al. 2006; Goldschmidt 2005; Teoh et al. 2012) and healthcare organizations considering the adoption of HIT face many financial, technical and cultural barriers. Understanding the factors that have significant effects on HIT adoption may assist practitioners as well as policy makers to develop effective solutions to make this process less painful but smoother for physicians and patients.

There have been numerous studies on the adoption and use of HIT systems (Ammenwerth et al. 2006; Anderson 2007; Ash et al. 2003; Ford et al. 2006; Kim and Chang 2007; Mayo-Smith and Agrawal 2007; Reardon and Davidson 2007). Most of the prior assessments have focused on one technology at a time such as electronic health record (Angst et al. 2010; Jha et al. 2009), computer physician order entry (Ash et al. 2003; Davidson and Chismar 2007), and telemedicine (Grigsby et al. 2007; Hu et al. 2002; Kifle et al. 2006). Researchers have examined the adoptions of these HIT at either organizational levels such as hospitals (Jha et al. 2009) or individual levels such as nurses (Eley et al. 2009; Lu et al. 2006), physicians (Hu et al. 1999; Snyder and Fields 2007) or patients (Ralston et al. 2007). Some researchers examined HIT adoption for specific tasks such as improvement in patient safety (Brooks et al. 2005) and reduction of medical errors (Bates et al. 1999; McAlearney et al. 2007). 
The scattering literature of HIT adoption implies a great need for synthesizing the knowledge through a systematic literature review (Kukafka et al. 2003). Such an effort is critical for forming a structured view of the knowledge in this field and building the basis for evidence-based decision making and future research in this area. Several studies have examined the literature of HIT adoption. Important and valuable as they are, there are a few shortcomings.

First, prior literature reviews mostly concern the adoption of a specific type of HIT, such as clinical decision support system (Kaplan 2001a; 2001b), electronic health record (Castillo et al. 2010; Cresswell and Sheikh 2009), and PDA (Lu et al. 2005) and Internet (Masters 2008) in a healthcare context. However, technological innovations are often adopted not just as separate technologies, but also as closely-related yet distinguishable elements in technology clusters (Kukafka et al. 2003). This is common in a healthcare context. In a case study that investigates healthcare processes, Carstens et al. (2009) found that multiple HIT systems are implemented in the process of emergency care, from patient admission, patient information collection, to emergency care providing. Weber-Jahnke et al. (2012) similarly noted that eHealth information systems manage a series of activities in the delivery of health care services from scheduling and billing to clinical decision support, and interoperability among the systems is important for the "continuum of care”. Thus, the adoption of different types of HIT may not be isolated but the factors motivating or inhibiting their adoption are expected to be rather related. Synthesizing the literature in a broader scope that extends to multiplex HIT, therefore, may produce additional insights to the field.

Second, HIT adoption is generally a collaborative activity that involves multiple users 
having access to the same system. For example, a networked e-prescription system involves collaborative use of the system among professionals at clinics and pharmacies to provide the needed medicines to patients. In this case, nurses in the clinics enter the prescriptions into the system and the pharmacists prepare the medicines according to the prescriptions as transmitted. Similarly a clinical decision support system involves not only physicians but also other clinicians in completing the clinical tasks (Kaplan 2001a; 2001b). Indeed the collaborative use of HIT among various user groups is common as the delivery of healthcare service demands joint effort of participants such as patients, nurses, physicians, pharmacists, and so on (Balka et al. 2012; Carstens et al. 2009; Davidson and Chismar 2007; He et al. 2012). This important dimension of collaboration among different user groups in HIT adoption, however, is largely neglected in the previous review of the HIT adoption literature.

Third, prior literature reviews tend to group adoption factors in an intuitive manner (Agarwal et al. 2010; Cresswell and Sheikh 2009; Ward et al. 2008). Although theoretical frameworks such as Technology Acceptance Model, social-technical perspective and theory of organizational change have been discussed in prior literature review (Creswell and Sheikh 2009; Holden and Karsh 2010), they were not used to guide the synthesis of the literature. A theory-guided review demonstrates several advantages. 1) The theory provides not only potential constructs in association with HIT adoption but also a structure for thinking logically about the relationships among these constructs (Denzin 1970; Shoemaker et al. 2004); 2) A theory-guided synthesis facilitates diagnosing gaps in the existing knowledge of HIT adoption and specifying future directions for inquiry. 
Fourth, literature review studies typically start with the identification of representative articles, followed by thorough examination of the articles, and evaluation and summary of key findings. A potential limitation of this approach in reviewing the HIT adoption literature is that this field is highly diverse; traditional approach of literature review may overlook potentially important factors that have yet to appear in main stream research and induce biased implications for future research.

Motivated to fill in the gaps in the prior literature review and identify overall knowledge structure in the HIT adoption literature, this study aims to 1) draw on a theoretical framework to guide the synthesis of the HIT adoption literature. The framework shall be general enough to encompass multiple HIT, users and tasks, and in the meantime be specific enough to include the collaborative structure among these critical elements in HIT adoption; (2) employ a structured exploratory approach to synthesize a large body of prior studies and to reveal the main themes in the extant HIT adoption literature; and (3) benchmark the existing knowledge in HIT adoption with the theoretical framework, and reflect on the implications for future research.

The rest of the paper is organized as follows. Section 2 provides an overview of theoretical models in the HIT adoption literature and discusses an activity perspective of HIT adoption. The activity perspective provides a framework to understand the conceptual elements in HIT adoption and the relationships among them. Section 3 describes the methodology and presents the results of the analysis from the activity perspective. Section 4 discusses the implications of the findings on future research of HIT adoption, followed by conclusion in Section 5 . 


\section{Theoretical Background}

\subsection{Existing Frameworks of HIT Adoption}

Influential theoretical models to explain HIT adoption include the Theory of Reasoned Action (TRA) (Fishbein and Ajzen 1975), the Theory of Planned Behavior (TPB) (Ajzen 1991), the Technology Acceptance Model (TAM) (Davis 1989), the Theory of Innovation Diffusion (TID) (Moore and Benbasat 1991; Rogers 1995), the Task-Technology-Fit (TTF) Model (Goodhue and Thompson 1995), and the Technology Organization and Environment (TOE) Model (Tornatzky et al. 1990). A brief summary of each of the theories is presented in Table 1. Each of the models concerns a specific aspect of HIT adoption issues, hence were drawn upon to develop more sophisticated models. For example, the theoretical underpinnings of the Unified Theory of Acceptance and Use of Technology (UTAUT) model include the TRA, TPB, TAM and TID among others (Hennington and Janz 2007).

Among these prominent theories employed in the HIT adoption literature, the TRA, TPB, TAM, TID and UTAUT were utilized mainly for individual level analysis (Ford et al. 2006; Hennington and Janz 2007; Holden and Karsh 2010; Hu et al. 1999), the TOE was more extensively used for organizational level analysis (Chang et al. 2007), and the TTF emphasizes fit between individual abilities, technology characteristics, and task requirements (Ammenwerth et al. 2006). Most of the models presented seem to concentrate rather strongly on attributes of individual users, attributes of technology, and/or attributes of organizations, neglecting an important attribute of HIT adoption, that is, HIT adoption involves collaborative use of HIT among user groups such as physicians, nurses, pharmacists, and patients for the completion of 
tasks that comprises the wholeness of tasks and working processes. This collaborative attribute is prevalent in the practice of HIT adoption, hence demands for careful examination to advance our understanding for the HIT adoption phenomenon. In the following we discuss an activity perspective of HIT adoption, which encompasses the collaborative nature of HIT adoption.

Table 1. Influential Theoretical Models in HIT Adoption

\begin{tabular}{|l|l|}
\hline Models & Summary \\
\hline $\begin{array}{l}\text { Theory of Reasoned Action } \\
\text { (TRA) }\end{array}$ & $\begin{array}{l}\text { An individual's intention to adopt HIT is determined by the } \\
\text { individual's personal attitude (favorable or unfavorable) toward } \\
\text { adopting the technology and subjective norm (the individual's } \\
\text { perceptions of what others expect him or her to do and the strength } \\
\text { of the motivation to comply with those expectations). }\end{array}$ \\
\hline $\begin{array}{l}\text { Theory of Planned } \\
\text { Behavior (TPB) }\end{array}$ & $\begin{array}{l}\text { An individual's intention to adopt HIT is determined by the } \\
\text { individual's personal attitude toward adopting the technology, } \\
\text { subjective norm and perceived behavioral control (the individual's } \\
\text { perceptions of resource and technology facilitating conditions and } \\
\text { perceptions of ability). }\end{array}$ \\
\hline $\begin{array}{l}\text { Technology Acceptance } \\
\text { Model (TAM) }\end{array}$ & $\begin{array}{l}\text { An individual's intention to adopt HIT is determined by perceived } \\
\text { usefulness and perceived ease of use of the HIT. }\end{array}$ \\
\hline $\begin{array}{l}\text { Theory of Innovation } \\
\text { Diffusion (TID) }\end{array}$ & $\begin{array}{l}\text { Individuals adopt HIT in a sequence and can be classified into } \\
\text { categories on the basis of their adoption behavior: innovators, early } \\
\text { adopters, early majority, late majority and laggards. }\end{array}$ \\
\hline $\begin{array}{l}\text { Task-Technology-Fit } \\
\text { (TTF) Model }\end{array}$ & $\begin{array}{l}\text { HIT is more likely to be adopted if the functionalities match (i.e., } \\
\text { fit) task requirements and individual abilities. }\end{array}$ \\
\hline $\begin{array}{l}\text { Technology Organization } \\
\text { and Environment (TOE) } \\
\text { Model }\end{array}$ & $\begin{array}{l}\text { HIT adoption decision is influenced by technological, } \\
\text { organizational and environmental factors. }\end{array}$ \\
\hline
\end{tabular}




\subsection{An Activity Perspective of HIT Adoption}

Activity Theory was initially developed by the Russian psychologist Vygotsky in the 1920's and was later elaborated by his followers, especially Leont'ev (for a review, see Kutti 1996). Unlike social psychological theories that take singular human action as the unit of analysis (Baron and Byrne 2000), Activity Theory views human behavior as an evolving activity system that is comprised of mediated relationships (Vygotsky 1981). According to the theory, an activity is composed of a series of actions - something a subject is conscious of doing with an immediate goal in mind - organized by the common motive to transform an object into an outcome (Leont'ev 1978). An activity can involve multiple subjects who collaborate with each other on the same object and form a community (Leont'ev 1989). How community members work on the same object is regulated by the division of labor, and how they interact with each other is regulated by rules (e.g. collective traditions, rituals and norms). The mediated relationships among subject, object and community was summarized by Engeström (1987) in the activity model shown in Figure 1. In the model, a dash line indicates that the relationship between two entities (e.g. subject and object) is mediated by the third entity (e.g. tool) connected with them with solid lines. 
Figure 1. An Activity Perspective of HIT Adoption

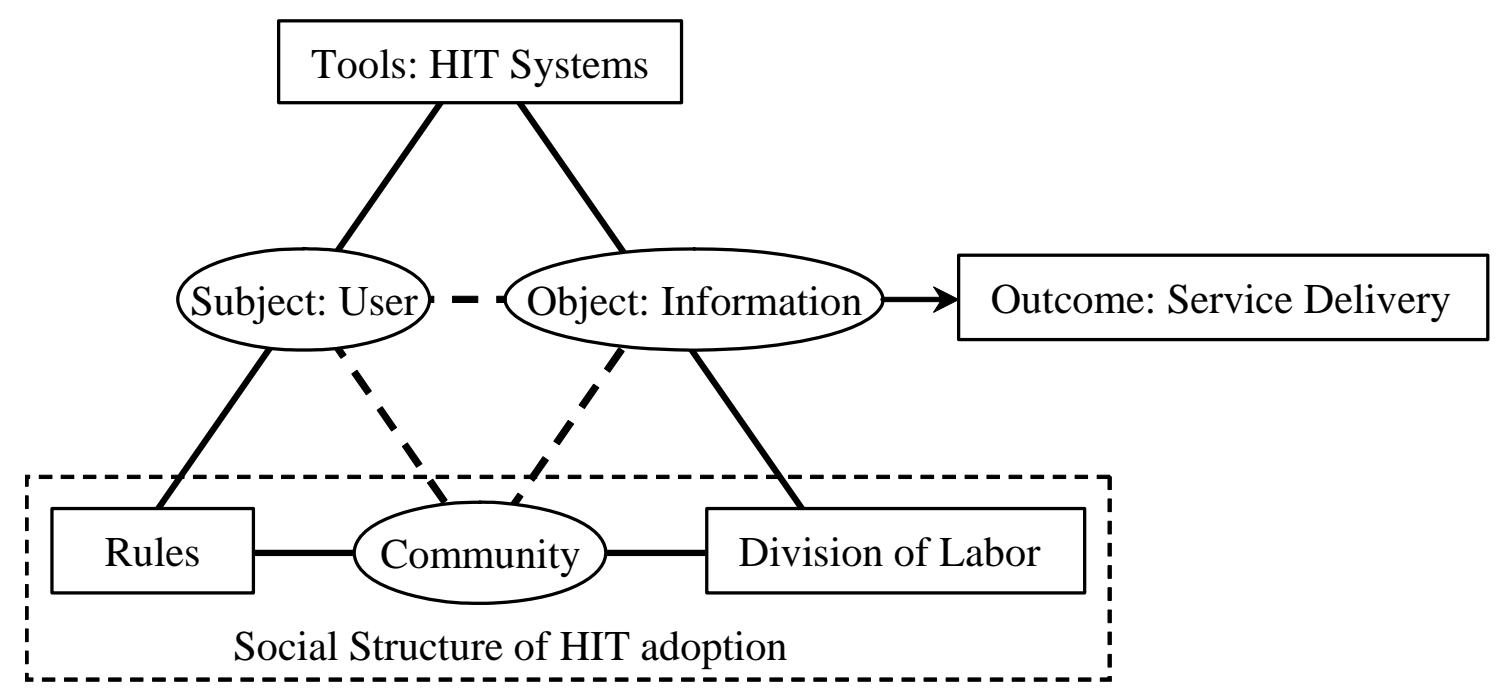

At the individual level, HIT adoption can be conceptualized as an activity in which the subject is a user, the object is healthcare-related information, and the tools are various HIT systems that the user employs to collect, transfer, process and store the digitized information. A person may have access to multiple systems for the delivery of a service. For example, a nurse can use computerized physician order entry (CPOE) to record the prescription given by a physician and send it through the electronic prescription (e-prescription) system to the pharmacy appointed by the client patient. The motive of such an activity is to obtain some desirable outcome, mainly facilitating and improving healthcare service delivery through the utilization of relevant information. In the above example, the use of different systems is for the same purpose of providing better medical services in terms of error reduction and efficiency enhancement through information digitization, sharing and reuse.

At the social level, HIT adoption can be regarded as a collaborative activity involving 
multiple subjects. That is, different users may have access to the same system and they form a community. The collaborative uses of e-prescription system and clinical decision support system illustrated in the introduction section are examples of HIT adoption at the social level. The social interaction and task cooperation among various users of the same system are regulated by rules and division of labor respectively, which constitute the social structure of HIT adoption. In the example of e-prescription system adoption, the division of labor is that the nurses in the clinics enter the prescriptions into the system and the pharmacists prepare the medicines according to the prescriptions as transmitted. The rules are the norms and standards that users need to follow together. For instance, a pharmacist may ask questions if there is anything unclear about a prescription, and the nurse who sent it need to make the clarification in a timely manner.

It should be noted that the individual and social levels of HIT adoption illustrated in the activity framework are inherently related (Davidson and Chismar 2007). This is because the delivery of healthcare service not only involves individual users such as patients, nurses, physicians and pharmacists, but also various user groups who collaborate with each other (Mouttham et al. 2012; Sadeghi et al. 2012). As a result, the adoption of HIT demands adoption at both individual level (adoption by patients, nurses, physicians or pharmacists) and social level (joint adoption by various user groups).

The capability of integrating HIT adoption at the individual and social levels is a remarkable advantage of the activity perspective of HIT adoption. In comparison to the activity perspective, technology usability studies mainly concern user-system relationship at the individual level (Eley et al. 2009; Lu et al. 2006). Although a few pioneer studies identified the 
need to examine HIT adoption at individual, group and organizational levels, they typically emphasize on the different needs of various stakeholders at the group level (Lapointe et al. 2011) and on getting the organization ready for change through planning, leadership and management, teamwork and communication, learning and evaluation, and realistic expectations at the organizational level (Cresswell and Sheikh 2009). The activity perspective of HIT adoption, in contrast, highlights the importance of understanding HIT adoption not only at individual level but also at social level concerning collaboration and joint effort among different user groups in HIT adoption, which is a critical but largely neglected dimension in previous HIT adoption literature. Furthermore, the activity perspective illustrates a framework of key elements in HIT adoption, hence can be rather instrumental in synthesizing the literature. Benchmarking the existing knowledge in HIT adoption with such a framework may also reveal future research directions from an activity perspective.

\section{Literature Synthesis}

Guided by the activity perspective, we synthesize the literature of HIT adoption by identifying different user groups (subjects), HIT systems (tools), purposes of HIT adoption (motives) and relevant social structures in the overall activity system of HIT adoption. We withdraw these elements and depict the linkages among these elements following the process of knowledge discovery via data mining (text mining in this study), which is a multiple-phase process that aims to automatically extract new knowledge from existing datasets (Mansingh et al. 2013). The text mining approach demonstrates several advantages in comparison to traditional 
approach of literature review. 1) Traditional approach of literature review manually analyzes and synthesizes a reasonable number of representative articles. Although valid for disciplines that are relatively cohesive, the traditional approach is limited for highly diverse and fragmented fields. As explained in the introduction, HIT adoption literature is highly dispersed across the types of HIT, the stakeholders and tasks involved, and the levels of analysis (Kukafka et al. 2003; Kaplan 2001b). It is therefore necessary to aggregate the large-volume of dispersed research articles at a higher semantic level in order to provide a clear view of the field. Text mining approach is apt for our purpose as it enables us to observe and identify clusters of articles based on their shared commonalities with other articles. 2) The proposed activity perspective of the HIT adoption phenomenon demands an exploratory approach that synthesizes the literature at a broad scope across technologies, user groups, communities and motives. Text mining techniques involves the process of structuring input text and deriving patterns within the structured data, hence are particularly relevant to this exploratory study.

\subsection{Data Collection}

This study bases the review of the HIT adoption literature on the existing articles, most of which were published between 1990 and 2009. The initial sample, comprising 5,460 articles, was collected by computerized searches through research databases, including PUBMED, MEDLINE and EMBASE, with key words "Healthcare”, "Information Technology", “Adoption”, "Diffusion" and "Implementation" in abstracts/titles. For each of the articles, the record included a unique identifier, the citation, abstract, authors' affiliation, and type of article (i.e. 
empirical research, conceptual discussion, review etc.). Not all articles were related to HIT adoption (e.g. technical discussions) and they were excluded. To screen the initial sample, two authors separately examined the abstracts and selected from the sample the relevant articles. The Measure of Agreement Kappa was 0.77, indicating an acceptable level of inter-rater reliability. The disagreements were resolved after the research team reexamined the articles. The final sample includes 979 articles, all of which concerns HIT adoption. These articles established the domain of content for subsequent text mining analyses.

\subsection{Computerized Text Mining}

Computerized text mining is an emerging technology characterized by a set of techniques and tools which seek to extract structured information through the identification and exploration of interesting patterns from relatively large-size textual data (Feldman and Sanger 2007). Text mining techniques typically draw on multiple disciplines such as information retrieval, data mining, machine learning, statistics, and computational linguistics. Recent advances in text mining techniques enable sophisticated applications in scholarly research, particularly in the medical domain (Jenssen et al. 2001; Tremblay et al. 2009; Ware et al. 2009).

\subsubsection{Literature Grouping}

SAS Text Miner program is employed to classify the articles into groups based on the relationships among the terms contained in the abstracts. The SAS Text Miner program is a popular text mining application according to the 2010 Rexer Analytics's Annual Data Miner 
Survey, the largest survey of data mining professionals in the industry. The algorithm classified the 979 sample articles into 14 groups, each defined by several descriptive terms as shown in Table 2. The descriptive terms were picked up by the computer program based on how frequent they appeared together in relevant articles.

Table 2: Literature Grouping Based on Key Concepts

\begin{tabular}{llll}
\hline \hline Group & Descriptive Terms & Emphasis & Frequency \\
\hline 1 & quality, +improve, healthcare, +organization & Quality Improvement & 147 (15\%) \\
2 & telemedicine, +service, more, +have & Telemedicine Service & $25(3 \%)$ \\
3 & +interaction, +device, +control, +interface & Interface/Interaction & 10 (1\%) \\
4 & internet, healthcare, +technology, +new, +have & Internet & $84(9 \%)$ \\
5 & +image, archiving, +picture, pacs, +communication & PACS & $17(2 \%)$ \\
6 & +assessment, +cost, +technology, +new, +method & Cost Assessment & $59(6 \%)$ \\
7 & +innovation, diffusion, +factor, +study, +technology & Innovation Diffusion & $54(6 \%)$ \\
8 & patient, care, information, +practice, health, clinical & Clinical Information & $176(18 \%)$ \\
9 & +digital, personal, +decision, clinical, care & Clinic Decision Support & 48 (5\%) \\
10 & +standard, +development, medicare, act, +policy & Policy/Standard/Act & $56(6 \%)$ \\
11 & ehr, electronic, +practice, +physician, +record & Electronic Health Record & 125 (13\%) \\
12 & +physician, +order, +error, +medication, prescription & CPOE \& E-Prescription & 69 (7\%) \\
13 & handheld, +nurse, +study, medical, +technology & Nursing Technology & 71 (7\%) \\
14 & education, +student, learning, +program, +computer & Health Education & 38 (4\%) \\
\hline
\end{tabular}

Note: PACS - Picture Archiving and Communication System; CPOE - Computerized Physician Order Entry. A glossary of the terms that have emerged as a result of the text mining is presented in the Appendix.

The descriptive terms in each category in Table 2 reveal the elements in the activity system of HIT adoption. Many studies focus on specific subjects in such activities, including: patient (category 8), physician (categories 11 and 12), nurse (category 13), and student (category 
14). Quite a few addressed the technical tools that people use, including: telemedicine (category 2), Internet (category 4), imaging (category 5), clinical decision support (category 9), electronic health record (category 11) and electronic prescription (category 12). Others concern the motives of such activities, including: healthcare quality improvement (category 1), cost assessment (category 6) and error reduction (category 12). Only a small portion of the articles addresses the social structure of HIT adoption, and they mainly focus on the policy/standard/act related to the rules regulating the use of such technologies (category 10).

\subsubsection{Conceptual Links}

The descriptive terms facilitate understanding of the main activity elements in the sample articles. A drawback of the descriptive terms is that only those with high frequency of appearance in the sample are extracted. Thus some important concepts that are related to HIT adoption could be overlooked because of their relatively low frequency of appearance in the sample. Therefore this study employs another text mining technique, the conceptual links, to enrich the pool of key concepts identified in the cluster analysis. The conceptual links technique utilizes predefined key words, that is, the descriptive terms, to search through the abstracts in the sample to find terms that are closely associated with the predefined key words. The resulted linkages among the concepts form a tree topology: the predefined key word is the root, the directly-related terms are the nodes, and the next indirectly-related terms are the leaves. Conceptually linked, these terms have a much broader coverage and are more meaningful than the descriptive terms identified in the previous literature grouping analysis. All the roots, nodes and leaves identified comprise the 
interconnected concepts associated with HIT adoption. Overall 25 sets of conceptual links were generated. Figure 2 illustrates the conceptual links generated using the key word "physician”1.

Figure 2. Conceptual Links of Physician

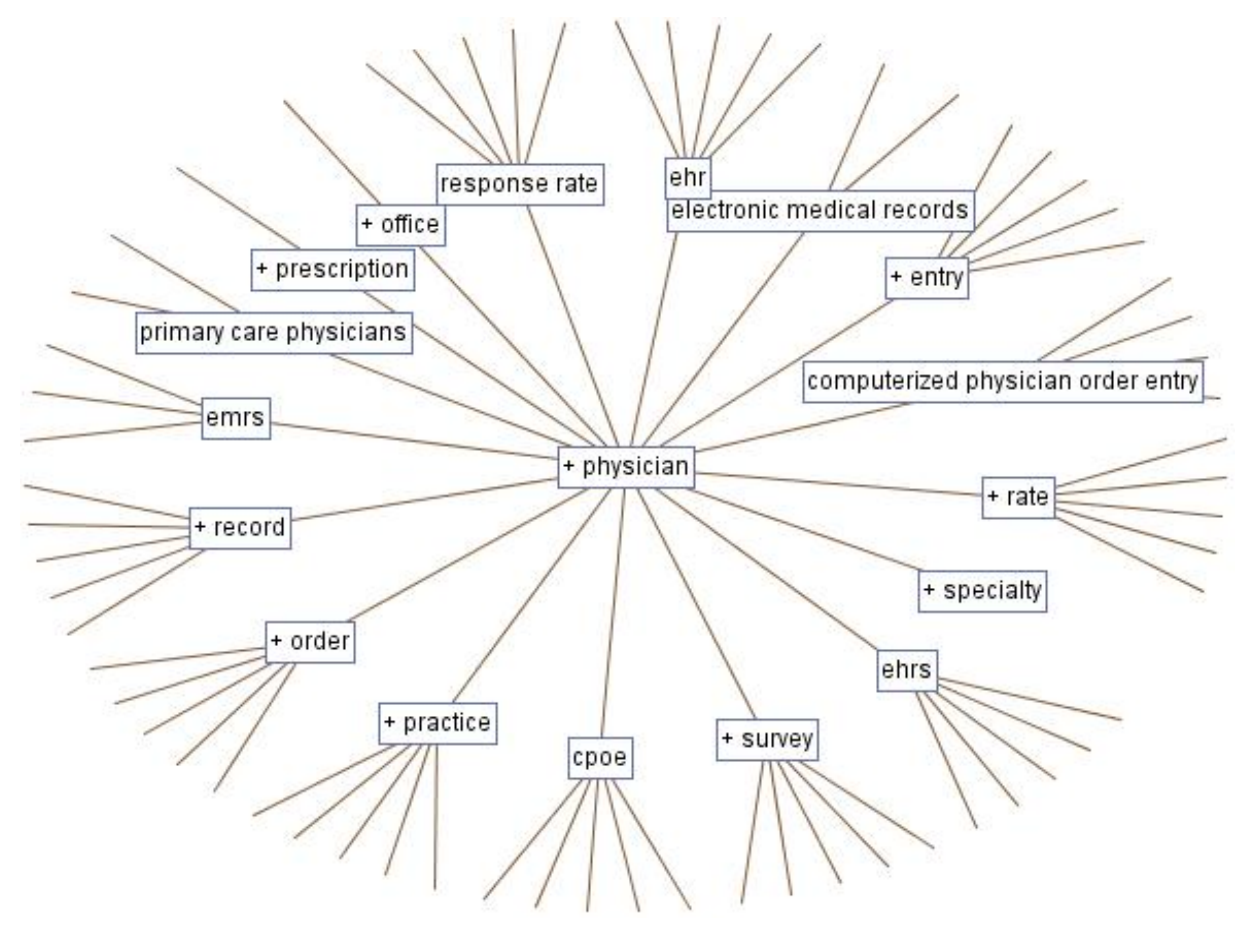

A closer look at these conceptual links reveals extensive connections among the conceptual links of different root terms through their common nodes and leaves. For example, the conceptual links of Physician and Health Information Technology share several common nodes and leaves such as Electronic Health Records, Electronic Medical Records, and Safety. These overlaps render valuable implications on how key concepts in the HIT adoption literature are connected and how the knowledge in this field is structured.

\footnotetext{
${ }^{1}$ Note that emrs and electronic medical records were identified as different nodes in Figure 2. This is because the conceptual links technique is designed to find terms that are closely associated with the root (the predefined key words), but its capability in grouping conceptually duplicative terms in the nodes and the leaves is limited. These duplicative terms were therefore manually cleaned later.
} 


\subsubsection{Concept Map}

Following the idea of knowledge accumulation by David Ausubel (Ausubel 1963; 1968), we construct a concept map of the HIT adoption literature through knitting the aforementioned conceptual links together based on their common shared nodes and leaves. The software used for this and the subsequent analyses is UCINET, a widely used tool for network analysis. Such concept maps have been proven to be an effective means of representing and communicating knowledge in various fields (Cañas et al. 2004; Coffey et al. 2002). The theoretical foundation for the generation of concept map can be traced back to the learning psychology of David Ausubel (1963; 1968). Ausubel's fundamental idea is that knowledge accumulation takes place by the integration of new concepts into existing conceptual frameworks. Hence mapping separate concepts helps organize existing knowledge, "even though the structure must be built up piece by piece with small units of interacting concept and propositional frameworks” (Novak and Cañas 2008). Thereafter Ausubel’s idea of knowledge accumulation has been broadly applied in disciplines such as education (Kinchin et al. 2000; Markham et al. 1994) and knowledge visualization (Cañas et al. 2005).

The concept map turns out to be a powerful tool that visualizes the key concepts and the linkages between them in the HIT adoption literature, which greatly facilitates the understanding of HIT adoption as a complex activity system. As shown in Figure 3, there are 41 key concepts in the map. Each node of concept represents an abstracted entity or a collective action. For example, the node "physician" in the map represents a general role rather than a particular 
person and there can be different individuals who play the same role in the activity system. According to Knoke and Kuklinski (1982), the advantage of constructing such a concept map is that "the complexity of the network is typically simplified; reducing a large number of actors into a smaller number of positions, since typically several empirical actors occupy the same position”.

Figure 3. Concept Map of HIT Adoption

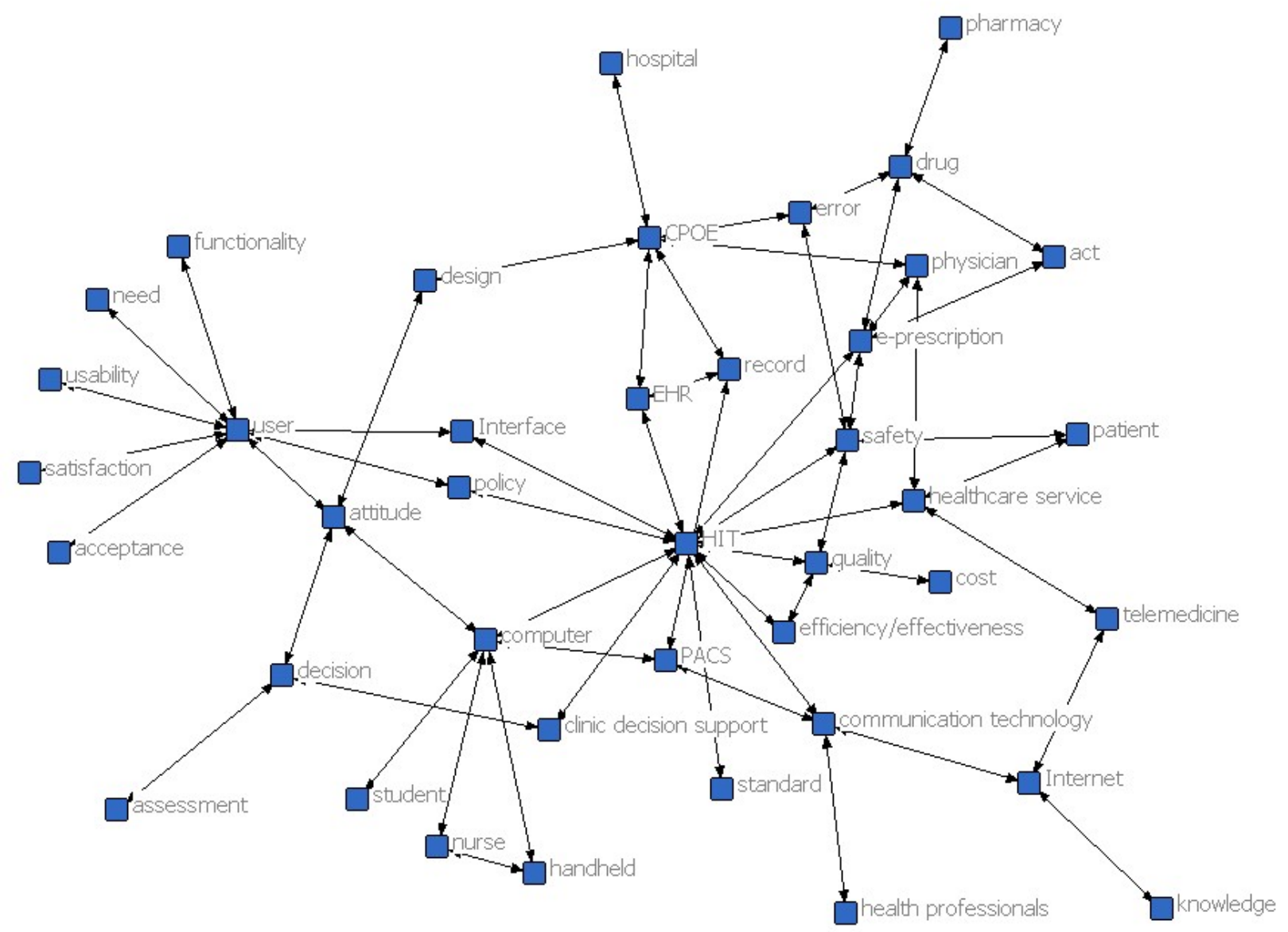

\subsubsection{Hierarchical Cluster Analysis of the Concept Map}

We employ hierarchical cluster analysis, a technique designed to assess the degree of similarity among nodes, to examine the patterns of the concept map. It classifies nodes based on 
how "close" they are to each other. Table 3 reports the result of hierarchical cluster analysis of seven clusters ${ }^{2}$. The result reinforces and refines the results obtained from the literature grouping analysis in Section 3.2.1. Clusters 1 through 5 report the major HIT examined in the literature: Telemedicine, E-prescription, EHR \& CPOE, Clinical decision support, and PACS \& end user devices.

Table 3. Hierarchical Cluster Analysis of the Concept Map

\begin{tabular}{cll}
\hline \hline Cluster & \multicolumn{1}{c}{ Concepts } & \multicolumn{1}{c}{ Cluster Summary } \\
\hline 1 & $\begin{array}{l}\text { communication technology, health professional, patient, } \\
\text { knowledge, Internet, healthcare service, telemedicine }\end{array}$ & Telemedicine \\
2 & $\begin{array}{l}\text { e-prescription, drug, act, error, safety, pharmacy } \\
3\end{array}$ & E-prescription \\
4 & assessment, clinic decision, decision & EHR \& CPOE \\
5 & attitude, computer, PACS, nurse, handheld, student & Clinical decision support \\
6 & usability, satisfaction, need, functionality, acceptance, user & PACS \& end-user devices \\
7 & efficiency/effectiveness, HIT, interface, policy, cost, & Institutional factors \\
& quality, standard & \\
\hline
\end{tabular}

The concepts within each of the first five clusters specify the elements in the activity of adopting a particular technology. For cluster 1, the main tools include telemedicine, Internet, and communication technology, the main subjects are health professionals, and the main motive is to share medical knowledge among them for delivering healthcare services to patients. For cluster 2, the main tools are e-prescription systems, the main subjects are pharmacy workers, and the main motive is to enhance drug safety and reduce medical errors. In addition, legal acts are identified as a prominent part of the social structure that regulates the use of this technology. For

\footnotetext{
${ }^{2}$ UCINET requires users to specify the number of clusters in running cluster analysis. The model with seven clusters yielded the best fit.
} 
cluster 3, the main tools are electronic health records (EHR) and computerized physician order entry (CPOE), the main subjects are physicians, and the main motive is to facilitate the entry, storage, and usage of medical records, especially in hospitals. Also, the design of such systems is recognized as a major topic in existing literature. For cluster 4, the main tools are clinic decision systems, the main subjects are not specified, and the main motive is to improve healthcare-related decision-making and relevant assessment. For cluster 5, the main tools are Picture Archiving and Communication Systems (PACS), computers and handhelds and the main subjects are nurses and students. Though the main motive is not specified, user attitude has been the focus of previous studies on such technologies.

Clusters 6 and 7 are pertinent to some general issues that are applicable to all kinds of technologies. The concepts in Cluster 6 are related to users' general considerations at the individual level. These concepts are commonly observed in the behavioral research of IT adoption, such as the technology acceptance research and the human computer interaction research. This indicates that the literature on HIT adoption has employed theories and methods from the general IT-related behavioral research. Compared with Cluster 6, Cluster 7 involves general institutional factors mostly beyond individual users: the concepts in Cluster 7 concern either the implementation of HIT in general (i.e. interface and standard) or the general performance of healthcare services due to the use of HIT (i.e. efficiency/effectiveness, policy, quality and cost). 


\subsubsection{Multidimensional Scaling}

To further explore the patterns underlying the various concepts across subjects, tools, motives and social structures in the concept map, we conduct Multidimensional Scaling (MDS) analysis on the concept map (Figure 4). MDS is useful in identifying the dimensions and the overall patterns in the concept map (Borgatti et al. 1999). The MDS analysis positions the concepts in the map in a two-dimension space. The values of the concepts along each dimension range from negative to positive. Concepts with positive coordinates on a dimension are included in that dimension and excluded otherwise. Figure 4 visualizes the relationships between the concepts and the two dimensions.

Figure 4. Two-Dimension Multidimensional Scaling

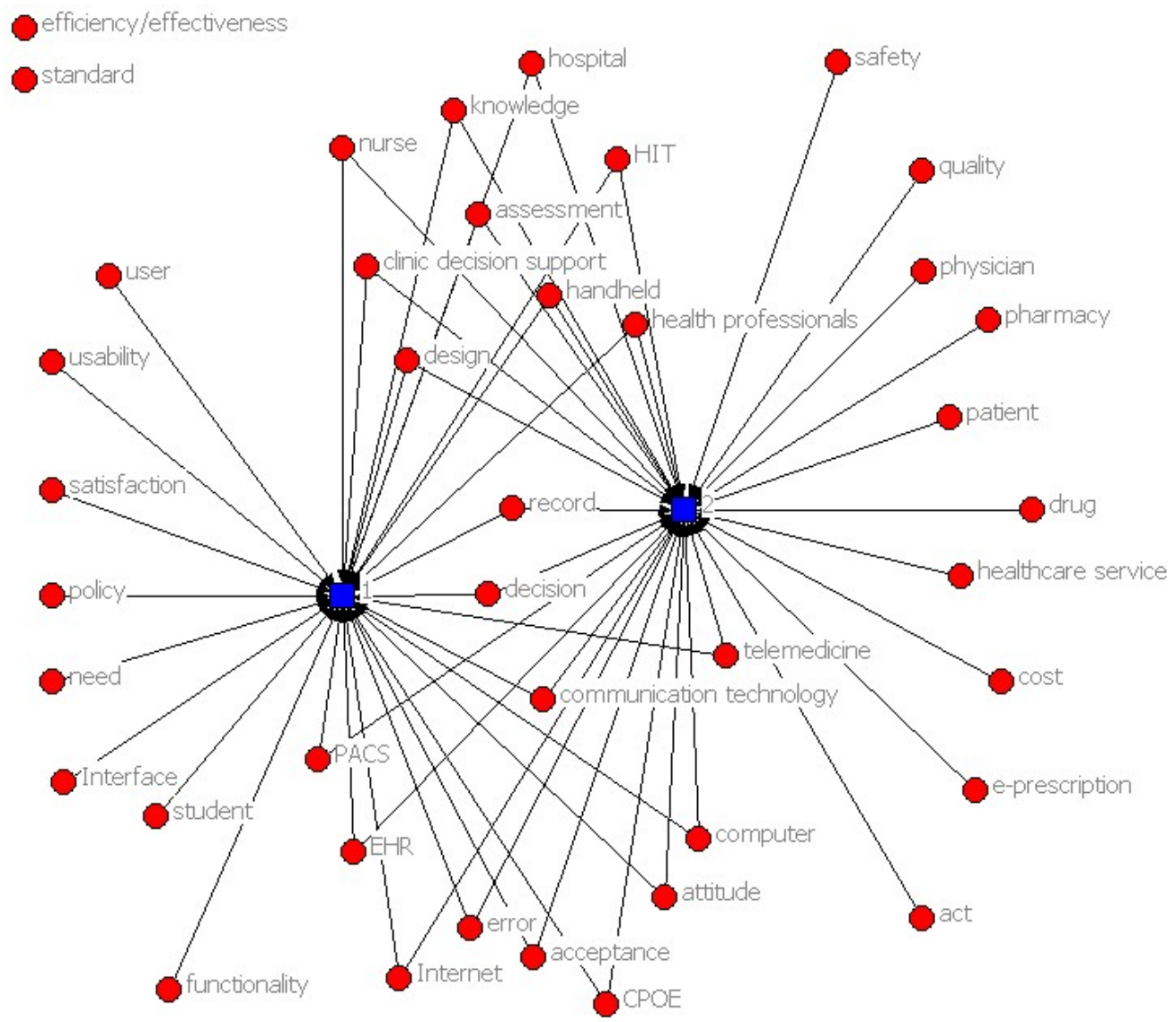


Most of the concepts are present in at least one dimension. The concepts that only emerge in Dimension 1, such as user, usability, satisfaction, need, interface and functionality, are commonly seen in the behavioral research of IT adoption. These concepts are not necessarily specific to HIT adoption, but rather general to all kinds of IT adoptions. Because most of these concepts are related to user behavior at the individual level, we name this dimension “Technology Usability”.

In contrast, the concepts that only emerge in Dimension 2 are specific to the delivery of healthcare services. For example, concepts such as safety, quality, and cost in this dimension are pertinent to healthcare outcomes, and concepts such as patient, physician, pharmacy, drug, and e-prescription are regarding entities involved in medication. We therefore name Dimension 2 “Service Delivery”.

The concepts present in both dimensions emphasize the use of IT for healthcare service deliveries. These concepts cover specific HIT (e.g. Clinic Decision Support, Telemedicine, EHR, PACS and CPOE), HIT infrastructure (e.g. computer, Internet, communication technology and handheld), technology implementation and application (e.g. design, record, decision, assessment and error), and user environment (e.g. hospital, healthcare professional, nurse, acceptance and attitude). Only efficiency/effectiveness and standard are excluded from the two dimensions. These two concepts are separated from the other concepts probably because they are very general requirements in the consideration of HIT adoption, and thus not particularly pertinent to either dimension. 
From an activity perspective, the two dimensions correspond to the two levels in the activity system of HIT adoption: individual level and social level. Technology usability is largely an individual-level topic as it mainly concerns the relationship between user and technology. Service delivery, on the other hand, is largely a social-level topic as it involves multiple subjects, such as physician and patient. However, the two dimensions cannot be isolated as there are more concepts shared between them than those specific to each. This supports the argument that HIT adoption is an undividable activity system in which various subjects, tools and objects interact with each other under certain social structures.

Note that the classification of the concepts to the two dimensions is based on the conceptual links derived from the existing studies on HIT and may not be fully consistent with the conventional wisdom. For example, “student”, “nurse” and "physician” are all HIT users, yet they are classified into different dimensions in the MDS result. This may be due to the distinct roles that they play in healthcare as described in the existing literature. Students mainly participate in IT learning and training but not necessarily in healthcare service delivery; hence the entity of student is closely related to the Technology Usability dimension. Physicians represent the decision makers in medication who are more pertinent to the Service Delivery dimension than to the Technology Usability dimension. Nurses are often regarded as the end-users of healthcare technologies for the delivery of services, and the concept is connected with both dimensions. Compared with the hierarchical cluster analysis, therefore, the classification of concepts resulted from MDS represents a higher-level abstraction of the semantic relationships contained in the literature of HIT adoption. 


\subsection{Validation of Computerized Text Mining Results}

Computerized text mining is a powerful technique that extracts structured information from large-size textual data (Feldman and Sanger 2007). Although the technique has been successfully applied in scholarly research in the medical domain (Jenssen et al. 2001; Tremblay et al. 2009; Ware et al. 2009), to the best of our knowledge, it has not been used to synthesize the HIT adoption literature. Therefore, a manual review will be helpful to validate the computer-generated results.

The human validation followed a four-step procedure. First, a test sample of 212 articles was randomly drawn from the original dataset (approximately one out of five) for manual review. The subset covered all the 14 groups in Table 2 that were identified through texting mining on all the abstracts in the original dataset. Second, Two graduate students were recruited to read the abstract of every article in the test sample, and extract up to three key words in each of the following three aspects of HIT adoption: technology in question, people/organization involved, and major issue examined. Separately, they generated two lists of keywords, each comprising four to six keywords for each article on average.

Third, the authors evaluated the degree of consensus between the two students. For each article, they counted the common keywords as well as the combined unique keywords. By aggregating the two counts across 212 articles, it was found that the two lists shared $86 \%$ in common (i.e. the ratio between the two sums), implying an acceptable level of consistency in the manually-identified keywords. Then, the pool of common keywords was compared to the list of computer-generated keywords (i.e. the descriptive terms in Table 2). The former covered all 
the latter except for "have" and "more". On the other hand, computer-generated keywords covered the majority of manually-identified ones. The results suggest that the keywords identified by Text Miner were generally meaningful.

Fourth, the two graduate students separately categorized the articles into the 14 groups in Table 2 based on the computer-generated descriptive terms and the common keywords manually identified for each article. The inter-rater reliability coefficients between each human participant and Text Miner were around 0.8 (Kappa=.82 and .79 respectively). Together with the keywords comparison, the consistency between human and computer classifications of HIT adoption publications suggests that the text mining results based on abstracts were generally valid.

\section{Discussions}

The results of the literature synthesis indicate that HIT adoption can be effectively viewed as an activity system that comprises different subjects (users), tools (HIT systems), objects (data and tasks) and social structures for the enhancement of healthcare efficiency and effectiveness. Activity Theory, as a theoretical lens to examine HIT adoption, is distinct from traditional socio-psychological paradigm. The difference lies in the unit of analysis: activity vs. action. Rooted in the socio-psychological paradigm, for instance, the technology acceptance research on HIT adoption focuses on the intention of using a technology and the unit of analysis is an action between a user (the subject) and a technology (the object) (Kim and Chang 2007). Whereas such a conceptualization is suitable for well-defined task environment, it is not sufficient for the investigation of technology adoption in contemporary dynamic environment in 
which there are different systems available for different tasks (Sun 2012). Activity theory provides an alternative to technology acceptance research as the unit of analysis is an activity that comprises multiple actions and involves different technologies as tools that users can choose for a certain purpose.

Thus, it is intuitive that the results of the synthesis are somewhat different from prior literature review on HIT adoption. Instead of revealing groups of factors such as finance, functionality, user, and environment (e.g. regulation) (DesRoches et al. 2008; Jha et al. 2009), the techniques employed in this study demonstrate abstractions of different scopes that can be accommodated within the activity perspective of HIT adoption. The core concepts identified through literature grouping reveals the elements in the activity system of HIT adoption; the concept map gives an overall picture of how the elements are related with each other; the hierarchical cluster analysis of the concept map uncovers different types of activities in HIT adoption categorized by the use of specific technologies as well as general user considerations and institutional factors; and the MDS reveals two major themes in the existing studies of HIT adoption at different levels of the activity system: technology usability at the individual level and service delivery at the social level. At the individual level, the literature primarily focuses on how each person uses an HIT application and involves human-computer interactions; at the social level, the literature mostly addresses how different users deliver healthcare services and comprises social interactions and task collaborations among HIT users. The two levels of activity systems are interdependent as they share the common concepts concerning user, technology, and information. 
The theory-based structured literature synthesis provides some insights on the current status of HIT adoption research. First, there have been much fewer studies on the social-level than on the individual-level concerns of HIT adoption. Most of the concepts identified in the computerized text mining are at the individual level; studies on collaborative activities are mostly missing in the literature. The few existing studies on the social structure in HIT adoption focus on institutional issues such as the policies, standards or legal acts related to the adoption of certain technologies.

Second, the existing studies have different emphases on the levels of analyses for different technologies. Majority of the studies has a focus on individual-level factors for most of the HIT applications. A focus on social-level factors is only found in a few other applications such as e-prescription. Unlike HIT applications that have more complicated user interfaces (e.g. EHR systems), e-prescription systems are relatively simple to use but involve different parties including clinicians, patients and pharmacists. Thus, social-level factors related to rules (e.g. Act) and division of labors (e.g. Safety) appear to be salient in the adoption of e-prescription systems.

The significant unbalance between studies at individual level and social level of HIT adoption calls for more investigations to the social structure in HIT adoption, especially the rules and division of labor involved in the collaboration among different users. Successful adoption of a single HIT may involve multiple users assuming different roles from the same or different organizations. For example, physicians from distant locations may use a telemedicine system for knowledge exchange and case discussion, and patient and medical staff may communicate through the same system in the delivery of in-home care. Such collaborative activities that 
involve a community of users are common in HIT-facilitated healthcare delivery. The corresponding social structure in the adoption of a specific HIT therefore demands special attention of both practitioners and scholars.

It needs to be noted that this study just took a snapshot of the HIT research showing its status up to a point of time. Yet the literature is growing at an astounding speed, hence is a moving target by itself. For instance, most of the previous studies on EHR applications focus on individual-level factors, but this may change in the near future when the adoption moves from the first stage of meaningful "data capture and sharing" at the fundamental level to the second stage of "advancing clinical processes" based on extensive health information exchange, and further to the third stage of "improved outcomes" at both the individual and population levels (Henricks 2011). Thus, it is expected that there will be more social-level analyses on the adoption of EHR in the near future.

\section{Conclusion}

During the last two decades, IT has become widely used in the healthcare sector and interest in HIT adoption grows significantly among researchers. The vast body of literature on health information technology (HIT) adoption features considerably heterogeneous adoption factors and demands for a synthesis of the knowledge in the field. Guided by the Activity Theory, this study views the HIT adoption phenomenon at two inherently related levels: adoption at individual level and adoption at social level. HIT adoption at the individual level can be conceptualized as an activity in which a user employs various HIT systems to collect, transfer, 
process and store digitized information. At the social level, HIT adoption can be viewed as a collaborative activity involving multiple users having access to the same system. Following a structured process of knowledge discovery via text mining, we investigate the state-of-the-art of the knowledge on HIT adoption from an activity perspective. The knowledge obtained is useful for healthcare researchers, practitioners and policy-makers to understand different aspects of HIT adoption and the current status of research. The theory-guided synthesis of literature also provides guidance on future research in this field.

This research contributes to the field of HIT adoption both empirically, by discovering knowledge via text mining, and theoretically, by synthesizing the findings with Activity Theory. The activity perspective and the computerized text mining techniques demonstrate an alignment between theory and methodology. The activity perspective argues that HIT adoption is not an isolated phenomenon by individual users and specific technologies, but an activity system involving social interactions and multiple technologies for a common purpose. Accordingly the text mining analysis covers a broad scope of the literature and identifies the elements in the activity system of HIT adoption. The network analysis further reveals the patterns in the map of core concepts and in particular, the social structure (i.e. the cooperation and sharing of healthcare information among various user groups that are governed by rules), if any, in the existing literature. 


\section{REFERENCES}

Agarwal, R., Gao, G., DesRoches, C., \& Jha, A.K. (2010). The digital transformation of healthcare: current status and the road ahead. Information Systems Research, 21, 796-809.

Ajzen, I. (1991). The theory of planned behavior. Organizational Behavior and Human Decision Processes, 50(2) 179-211.

Ammenwerth E., Iller, C., \& Mahler, C. (2006). IT-adoption and the interaction of task, technology and individuals: A fit framework and a case study. BMC Medical Informatics and Decision Making, 6(3), available from http://www.biomedcentral.com/content/pdf/1472-6947-6-3.pdf.

Anderson, J.G. (2007). Social, ethical and legal barriers to E-health. International Journal of Medical Informatics, 76(5), 480-483.

Angst, C.M., Agarwal, R., Sambamurthy, V., \& Kelley, K. (2010). Social contagion and information technology diffusion: the adoption of electronic medical records in U.S. hospitals. Management Science, 56(12), 19-1241.

Ash, J.S., Stavri, P.Z., \& Kuperman, G.J. (2003) Consensus statement on considerations for a successful CPOE implementation. Journal of the American Medical Informatics Association, 10(3), 229-234.

Ausubel, D.P. (1963). The Psychology of Meaningful Verbal Learning. Oxford, England: Grune \& Stratton.

Ausubel, D.P. (1968). Educational Psychology: A Cognitive View. New York: Holt, Rinehart and Winston.

Balka, E., Whitehouse, S., Coates, S.T., \& Andrusiek, D. (2012). Ski hill injuries and ghost charts: Socio-technical issues in achieving e-Health interoperability across jurisdictions. Information Systems Frontiers, 14(1), 19-42.

Baron, R.A., \& Byrne, D. (2000). Social Psychology (9th ed.). Boston: Allyn and Bacon.

Bates, D.W., Teich, J.M., Lee, J., Seger, D., Kuperman, G.J., Ma'Luf, N., et al. (1999). The impact of computerized physician order entry on medication error prevention. Journal of the American Medical Informatics Association, 6(4), 313-321.

Berman, M. \& Fenaughty, A. (2005). Technology and managed care: patient benefits of telemedicine in a rural health care network. Health Economics, 14 (6), 559-573. 
Berner, E. S. (2007). Clinical Decision Support Systems: Theory and Practice $\left(2^{\text {nd }}\right.$ ed.). New York, NY: Springer.

Bhattacherjee, A., Hikmet, N., Menachemi, N., Kayhan, V., \& Brooks, R.G. (2006). The differential performance effects of healthcare information technology adoption. Information Systems Management, 24(1), 5-14.

Borgatti, S.P., Everett, M.G., \& Freeman, L.C. (1999). Ucinet 5.0 for Windows. Natick: Analytic Technologies.

Brailer, D., \& Thompson, T. (2004). Health IT strategic framework. Washington, DC: Department of Health and Human Services.

Brooks, R.G., Menachemi, N., Burke, D., \& Clawson, A. (2005). Patient safety-related information technology utilization in urban and rural hospitals. Journal of Medical Systems, 29(2), 103-109.

Cañas, A., Carff, R., Hill, G., Carvalho, M., Arguedas, M., Eskridge, T., et al. (2005). Concept maps: Integrating knowledge and information visualization. Knowledge and Information Visualization, 3426, 181-184.

Cañas, A.J., Hill, G., Carff, R., Suri, N., Lott, J., Gómez, G., et al. (2004). Cmaptools: A knowledge modeling and sharing environment. In the Proceedings of the First International Conference on Concept Mapping (Pamplona, Spain), 1, 125-133.

Carstens, D. S., Patterson, P., Laird, R., \& Preston, P. (2009). Task analysis of healthcare delivery system. Journal of Engineering and Technology Management, 6, 15-27.

Castillo, V.H., Martínez-García, A.I., \& Pulido, J.R.G. (2010). A knowledge-based taxonomy of critical factors for adopting electronic health record systems by physicians: a systematic literature review. BMC Medical Informatics \& Decision Making, 10(1), 60-76.

Chang, I., Hwang, H.G., Hung, M.C., Lin, M.H., \& Yen, D.C. (2007). Factors affecting the adoption of electronic signature: Executives' perspective of hospital information department. Decision Support Systems, 44(1), 350-359.

Choplin, R., (1992). Picture archiving and communication systems: an overview. Radiographics 12 (1), 127-129.

Coffey, J.W., Hoffman, R.R., Cañas, A.J., \& Ford, K.M. (2002). A concept map-based knowledge modeling approach to expert knowledge sharing. In the Proceedings of International Conference on Information and Knowledge Sharing (Virgin Islands), 212-217.

Cresswell, K., \& Sheikh, A. (2009). The NHS care record service (NHS CRS): 
Recommendations from the literature on successful implementation and adoption. Informatics in Primary Care, 17(3), 153-160.

Davidson, E.J., \& Chismar, W.G. (2007). The interaction of institutionally triggered and technology-triggered social structure change: An investigation of computerized physician order entry. MIS Quarterly, 31(4), 739-758.

Davis, F.D. (1989). Perceived usefulness, perceived ease of use, and user acceptance of information technology. MIS Quarterly, 13(3), 319-340.

Denzin, N.K. (1970). The Research Act: A Theoretical Introduction to Sociological Methods. Chicago, IL: Aldine Publishing Company.

DesRoches, C. M., Campbell, E. G., Rao, S. R., Donelan, K., Ferris, T. G., Jha, A. K., et al. (2008). Electronic health records in ambulatory care-A national survey of physicians. New England Journal of Medicine, 359(1), 50-60.

Eley, R., Fallon, T., Soar, J., Buikstra, E., \& Hegney, D. (2009). Barriers to use of information and computer technology by Australia's nurses: A national survey. Journal of Clinical Nursing, 18(8), 1151-1158.

Engeström, Y. (1987). Learning by Expanding: An Activity-Theoretical Approach to Developmental Research. Orienta-konsultit: Helsinki.

Feldman, R., \& Sanger, J. (2007). The Text Mining Handbook: Advanced Approaches in Analyzing Unstructured Data. New York: Cambridge University Press.

Fishbein, M., \& Ajzen, I. (1975). Belief, Attitude, Intention and Behaviour: An Introduction to Theory and Research. Reading, MA: Addison-Wesley.

Ford, E.W., Menachemi, N., \& Phillips, M.T. (2006). Predicting the adoption of electronic health records by physicians: When will health care be paperless. Journal of the American Medical Informatics Association, 13(1), 106-112.

Goldschmidt, P. G. (2005). HIT and MIS: implications of health information technology and medical information systems. Communications of the ACM, 48(10), 68-74.

Goodhue, D. L., \& Thompson, R. L. (1995). Task-technology fit and individual performance. MIS Quarterly, 19(2), 213-236.

Grigsby, B., Brega, A.G., Bennett, R.E., Devore, P.A., Paulich, M.J., Talkington, S.G., et al. (2007). The slow pace of interactive video telemedicine adoption: the perspective of telemedicine program administrators on physician participation. Telemedicine and e-Health, 13(6), 645-656. 
Grossman, J. M., Gerland, A., Reed, M. C., \& Fahlman, C. (2007). Physicians’ experiences using commercial e-prescribing systems. Health affairs, 26(3), 393-404.

Gunter, T. D. \& Terry, N. P. (2005). The emergence of national electronic health record architectures in the United States and Australia: Models, costs, and questions. Journal of Medical Internet Research, 7 (1): e3.

He, D., Yang, J., Compton, M., \& Taylor, K. (2012). Authorization in cross-border eHealth systems. Information Systems Frontiers, 14, 43-55.

Hennington, A.H., \& Janz, B.D. (2007). Information Systems and healthcare XVI: physician adoption of electronic medical records: applying the UTAUT model in a healthcare context. Communications of the Association for Information Systems, 19(5), 60-80.

Henricks, W. H. (2011). "Meaningful use" of electronic health records and its relevance to laboratories and pathologists. Journal of pathology informatics, 2(7).

Holden, R.J., \& Karsh, B. (2010). The technology acceptance model: Its past and its future in health care. Journal of Biomedical Informatics, 43(1), 159-172.

Hu, P.J., Chau, P., \& Sheng, O. (2002). Adoption of telemedicine technology by health care organizations: an exploratory study. Journal of Organizational Computing and Electronic Commerce, 12(3), 197-221.

Hu, P.J., Chau, P., Sheng, O., \& Tam, K. (1999). Examining the technology acceptance model using physician acceptance of telemedicine technology. Journal of Management Information Systems, 16(2), 91-112.

Jenssen, T.K., Laegreid, A., Komorowski, J., \& Hovig, E. (2001). A literature network of human genes for high-throughput analysis of gene expression. Nature genetics, 28(1), 21-28.

Jha, A.K., DesRoches, C.M., Campbell, E.G., Donelan, K., Rao, S.R., Ferris, T.G., et al. (2009). Use of electronic health records in U.S. hospitals. New England Journal of Medicine, 360(16), 1628-1638.

Kaplan, B. (2001a). Evaluating informatics applications--clinical decision support systems literature review. International Journal of Medical Informatics, 64(1), 15-37.

Kaplan, B. (2001b). Evaluating informatics applications--some alternative approaches: theory, social interactionism, and call for methodological pluralism. International Journal of Medical Informatics, 64(1), 39-56. 
Kifle, M., Mbarika, V., \& Datta, P. (2006). Interplay of cost and adoption of tele-medicine in Sub-Saharan Africa: The case of tele-cardiology in Ethiopia. Information Systems Frontiers, 8(3), 211-223.

Kim, D., \& Chang, H. (2007). Key functional characteristics in designing and operating health information websites for user satisfaction: An application of the extended technology acceptance model. International Journal of Medical Informatics, 76(11), 790-800.

Kinchin, I.M., Hay, D.B., \& Adams, A. (2000). How a qualitative approach to concept map analysis can be used to aid learning by illustrating patterns of conceptual development. Educational Research, 42(1), 43-57.

Knoke, D., \& Kuklinski, J.H. (1982). Network Analysis. Sage Publications.

Kukafka, R., Johnson, S.B., Linfante, A., \& Allegrante, J.P. (2003). Grounding a new information technology implementation framework in behavioral science: a systematic analysis of the literature on IT use. Journal of Biomedical Informatics, 36(3), 218-227.

Kuperman, G. J., \& Gibson, R. F. (2003). Computer physician order entry: benefits, costs, and issues. Annals of Internal Medicine, 139(1), 31-39.

Kutti, K. (1996). Activity theory as a potential framework for human-computer interaction. In B.A. Nardi (ed.) Context and Consciousness: Activity Theory and Human-Computer Interaction (pp. 17-44). Cambridge: MIT Press.

Lapointe, L., Mignerat, M., \& Vedel, I. (2011). The IT productivity paradox in health: A stakeholder's perspective. International Journal of Medical Informatics, 80(2), 102-115.

Leont'ev, A.N. (1978). Activity, Consciousness and Personality. Englewood Cliffs: Prentice-Hall.

Leont'ev, A.N. (1989). The problem of activity in the history of Soviet psychology. Soviet Psychology, 27(1), 22-39.

Lu, Y.C., Xiao, Y., Mills, M.E., Soeken, K., \& Vaidya, V. (2006). Top barriers and facilitators to nurses’ PDA adoption. In AMIA Annual Symposium Proceedings, 2006: 1016.

Lu, Y.C., Xiao, Y., Sears, A., \& Jacko, J.A. (2005). A review and a framework of handheld computer adoption in healthcare. International Journal of Medical Informatics, 74(5), 409-422.

Mansingh, G., Rao, L., Osei-Bryson, K., \& Mills, A. (2013). Profiling internet banking users: A knowledge discovery in data mining process model based approach. Information Systems Frontiers, January 2013. 
Markham, K.M., Mintzes, J.J., \& Jones, M.G. (1994). The concept map as a research and evaluation tool: Further evidence of validity. Journal of Research in Science Teaching, 31(1) 91-101.

Masters, K. (2008). For what purpose and reasons do doctors use the Internet: A systematic review? International Journal of Medical Informatics, 77(1): 4-16.

Mayo-Smith, M.F., \& Agrawal, A. (2007). Factors associated with improved completion of computerized clinical reminders across a large healthcare system. International Journal of Medical Informatics, 76(10), 710-716.

McAlearney, A.S., Chisolm, D.J., Schweikhart, S., Medow, M.A., \& Kelleher, K. (2007). The story behind the story: Physician skepticism about relying on clinical information technologies to reduce medical errors. International Journal of Medical Informatics, 76(11), 836-842.

Menon, N.M., \& Lee, B. (2000). Cost control and production performance enhancement by IT investment and regulation changes: Evidence from the healthcare industry. Decision Support Systems, 30(2), 153-169.

Menon, N.M., Lee, B., \& Eldenburg, L. (2000). Productivity of information systems in the healthcare industry. Information Systems Research, 11(1), 83-92.

Miller, C. (1993). The electronic medical record: A definition and discussion. Topics in Health Information Management, 13(3), 20-29.

Moore, G.C., \& Benbasat, I. (1991). Development of an instrument to measure the perceptions of adopting an information technology innovation. Information Systems Research, 2(3), 192-222.

Mouttham, A., Kuziemsky, C., Langayan, D., Peyton, L., \& Pereir, J. (2012). Interoperable support for collaborative, mobile, and accessible health care. Information Systems Frontiers, 14(1), 73-85.

Novak, J.D., \& Cañas, A.J. (2008). The Theory Underlying Concept Maps and How to Construct and Use Them. Florida Institute for Human and Machine Cognition, 284.

Ralston, J.D., Carrell, D., Reid, R., Anderson, M., Moran, M., \& Hereford, J. (2007). Patient web services integrated with a shared medical record: Patient use and satisfaction. Journal of the American Medical Informatics Association, 14(6), 798-806.

Reardon, J.L., \& Davidson, E. (2007). An organizational learning perspective on the assimilation of electronic medical records among small physician practices. European Journal of Information Systems, 16, 681-694. 
Rogers, E.M. (1995). Diffusion of Innovations. New York, NY: The Free Press.

Sadeghi, P., Benyoucef, M., \& Kuziemsky, C. (2012). A Mashup based framework for multi level healthcare interoperability. Information Systems Frontiers, 14(1), 57-72.

Shoemaker, P.J., Tankard, J.W. Jr., \& Lasorsa, D.L. (2004). How to Build Social Science Theories. Thousand Oaks, CA: Sage Publications.

Sittig, D. F. \& Steed, W. W. (1994). Computer based physician order entry: the state of the art. Journal of the American Medical Informatics Association, 1(2), 108-123.

Snyder, R., \& Fields, W. Community hospital physician adoption of a CPOE system: perceptions of readiness, usefulness, and satisfaction. In AMIA Annual Symposium Proceedings, 2007, 1117.

Sun, J. (2012). Why different people prefer different systems for different tasks: An activity perspective on technology adoption in a dynamic user environment. Journal of the American Society for Information Science and Technology, 63(1), 48-63.

Teoh, S.Y., Pan, S.L., \& Ramchand, A.M. (2012). Resource management activities in healthcare information systems: A process perspective. Information Systems Frontiers, 14(3), 585-600.

Tornatzky, L.G., Fleischer, M., \& Chakrabarti, A.K. (1990). The Processes of Technological Innovation (Vol. 273). Lexington, MA: Lexington Books.

Tremblay, M., Berndt, D., Luther, S., Foulis, P., \& French, D. (2009). Identifying fall-related injuries: Text mining the electronic medical record. Information Technology and Management, 10(4), 253-265.

Vygotsky, L.S. (1981). The instrumental method in psychology. In: J.V. Wertsch (ed.) The Concept of Activity in Soviet Psychology (pp. 134-143). Armonk: Sharpe.

Ward, R., Stevens, C., Brentnall, P., \& Briddon, J. (2008). The attitudes of health care staff to information technology: a comprehensive review of the research literature. Health Information \& Libraries Journal, 25(2), 81-97.

Ware, H., Mullett, C.J., \& Jagannathan, V. (2009). Natural language processing framework to assess clinical conditions. Journal of the American Medical Informatics Association, 16(4), 585-589.

Weber-Jahnke, J., Peyton, L, \& Topaloglou, T. (2012). eHealth system interoperability. Information Systems Frontiers, 14(1), 1-3. 


\section{Appendix: Glossary of Terms}

Health Information Technology (HIT): The umbrella term that refers to the application of information processing involving both computer hardware and software that deals with the storage, retrieval, sharing, and use of health care information, data, and knowledge for communication and decision making (Brailer, \& Thompson, 2004).

Picture Archiving \& Communication Systems (PACS): A medical imaging technology which provides economical storage of and convenient access to images from multiple sources (Choplin, 1992).

Computerized Physician Order Entry (CPOE): An application that allows healthcare providers in hospitals and clinics to use computers to enter medical orders (e.g. medication, laboratory, admission, radiology, referral, and procedure orders) electronically for the treatment of their patients (Kuperman \& Gibson, 2003; Sittig \& Steed, 1994).

Electronic Prescription (E-prescription): An application that allows a physician, physician assistant, or nurse to transmit a new or renewal prescription to a pharmacy rather than filling out a paper prescription (Grossman et al., 2007).

Telemedicine: The use of information and communication technologies (ICT) to help remote areas (e.g. rural communities) eliminate distance barriers and improve access to medical services (Berman \& Fenaughty, 2005).

Clinical Decision Support Systems (CDSS): An interactive decision support system (DSS) designed to help physicians, physician assistants, and nurse practitioners make decisions, such as determining diagnosis based on patient data (Berner, 2007).

Electronic Medical Records (EMR): Digital versions of paper charts that contain the medical and treatment history of the patients from one practice for providers to use for diagnosis and treatment (Miller, 1993).

Electronic Health Records (EHR): An evolving concept that generally refers to the systematic collection of digital records about individual patients or populations for the use and exchange of them across different health care settings (Gunter \& Terry, 2005). 